\title{
The technique of total mitral valve replacement
}

\author{
VIKING OLOV BJÖRK AND ALOIS MEISSL \\ From the Department of Thoracic Surgery, University Hospital, Uppsala, Sweden
}

Total mitral valve replacement was first successfully accomplished by Starr and Edwards (1961) using a ball valve prosthesis. We have adopted their method for patients in whom the pathological changes make it impossible to obtain a mobile anterior mitral leaflet due to calcifications or shortened fused chordae tendineae. This paper describes an instrument that holds the ball valve prosthesis incompetent during its fixation. The holder can be unscrewed and removed before the last stitch in the left atrium is tied.

\section{METHOD}

We prefer the right-sided approach subcostally under the fifth rib. The mitral valves with chordae tendineae and papillary muscles are resected in one block

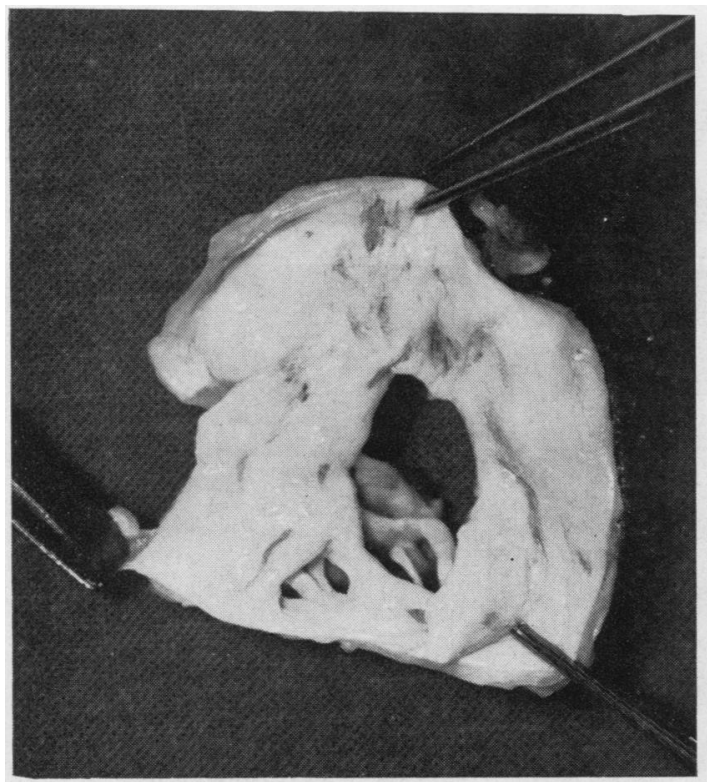

(a) leaving a short rim of vaive tissue close to the annulus (Figs. 1a and 1b). Heavy silk mattress sutures are used (20-24), placed in such a way that the knots are covered beneath the flap of valve tissue attached to the annulus (Ellis and Callahan, 1961) to diminish thrombosis around the knots (Fig. 2).

As the heart is beating, it is important to keep the valve incompetent in order to prevent air embolism. A long forceps was first used to keep the valve incompetent, but on one occasion it caused a hole in the anterior wall of the left ventricle. After division of the sternum the hole was closed by mattress sutures under a large branch of the left descending coronary artery. Starr has reported a similar accident. We have therefore constructed a special holder for the ball valve prosthesis (Fig. 3a-c). The holder keeps the ball pressed down in the cage and is used as a handle when all the sutures are inserted. It is also used to push the valve down into position and keeps the valve

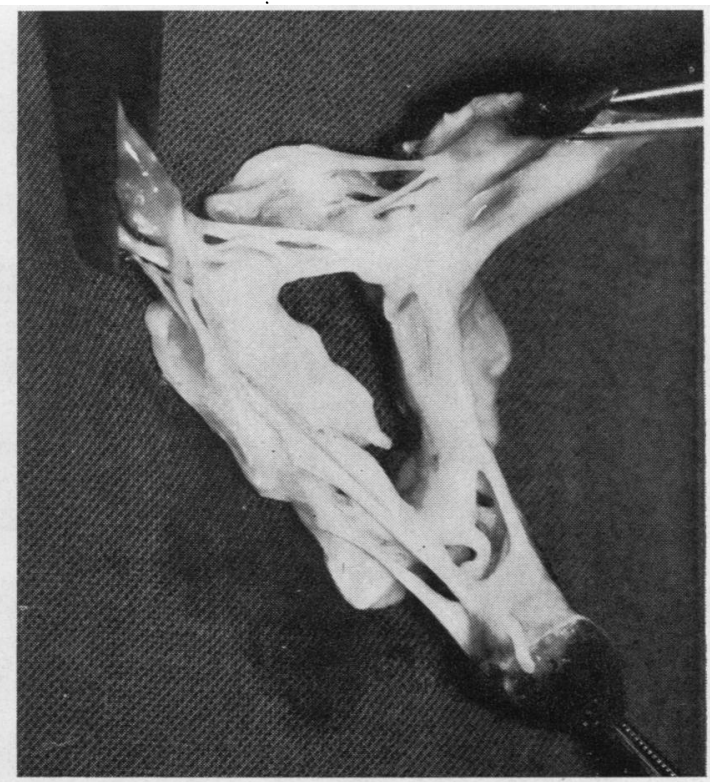

(b)

FIG. 1. The mitral ostium viewed (a) from the left atrium where the thick and immobile cusps made a total valve resection necessary, and (b) from the left ventricle with fused chordae tendineae which are thick and shortened, making the anterior mitral valve immobile. 


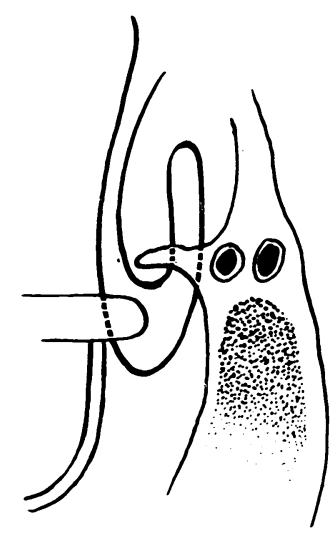

FIG. 2. Diagram showing how the sutures are placed so that the knots are covered beneath the flap of valve tissue attached to the annulus.

incompetent while the sutures are tied. It can then be unscrewed and removed as soon as the atrium has been filled with blood, and before the last sutures in the left atrial incision have been tied.

All patients needing total valve replacement are kept on post-operative respiratory treatment for approximately one week. Anticoagulant therapy is begun on the sixth day and continued for life.

\section{DISCUSSION}

In our first series of 35 cases, annuloplasty was used in 14 ; one patient died and eight improved. Annuloplasty cannot be used on too small or too large an orifice. Stenosis must be avoided. If mitral regurgitation is not completely abolished when the orifice has been narrowed down to $1 \frac{3}{4}$ fingers breadth, the method should not be used.

The posterior Ivalon cushion prosthesis first described by Lillehei, Gott, DeWall, and Varco
(1958) was used in seven cases; three patients died and three improved. It is necessary to have a mobile anterior mitral leaflet as the cushion does not move.

We only use total mitral valve replacement when annuloplasty and a posterior cushion cannot give a good result. Of the 14 patients who had total valve replacements, five died and eight are improved. At operation air embolism was a danger until a special incompetence holder was constructed. The late danger of embolism is diminished by the suture technique and anticoagulants. We have, however, encountered death from embolism, due to thrombosis around the prosthesis in the left atrium. The patient was under anticoagulant treatment and had a very low prothrombin time. No patients have survived who had hearts over $1,000 \mathrm{ml} . / \mathrm{m} .^{2}$ body surface.

\section{SUMMARY}

A special incompetence holder for the Starr mitral ball valve prosthesis is described. Other important technical details of total mitral valve replacement are the suture technique, the post-operative respirator, and anticoagulant treatment.

\section{REFERENCES}

Ellis, F. H., and Callahan, J. A. (1961). Clinical application of a flexible monocusp prosthesis: Report of a case. Proc. Mayo Clin., 36, 605 .

Lillehei, C. W., Gott, V. L., DeWall, R. A., and Varco, R. L. (1958). The surgical treatment of stenotic or regurgitant lesions of the mitral and aortic valves by direct vision utilizing a pump-oxygenator. $J$. thorac. Surg., 35, 154

Starr, A., and Edwards, M. L. (1961). Mitral replacement; the shielded ball valve prosthesis. Ibid., 42, 673 .

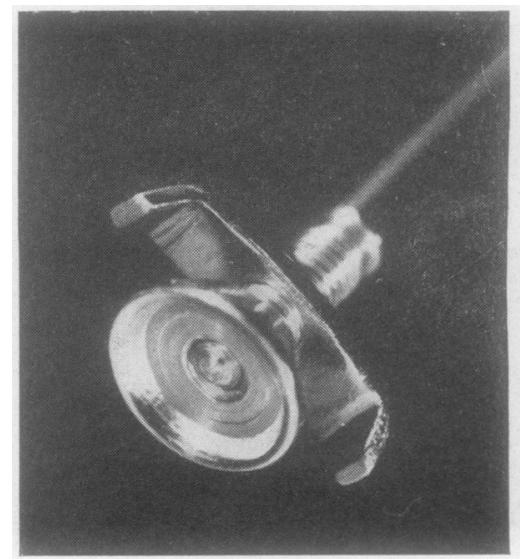

(a)

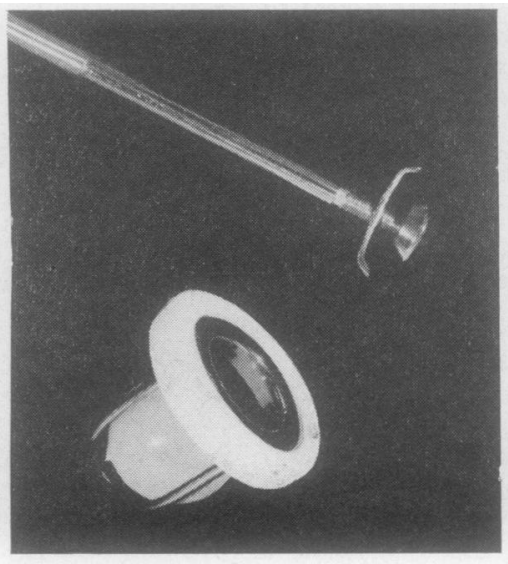

(b)

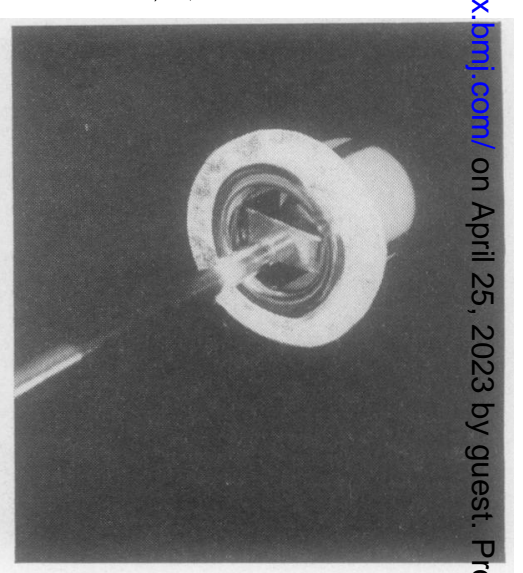

(c)

FIG. 3. The valve holder. (a) The head will press the ball down in the cage. It can easily be unscrewed under the level $\stackrel{\bigcirc}{\Phi}$ of blood; (b) the holder together with a Starr mitral ball valve; $(c)$ the holder applied in such a way as to make 0 the mitrcl ball valve prosthesis incompetent. 